\title{
Hyperglycemia suppresses cardiac stem cell homing to peri-infarcted myocardium via regulation of ERK1/2 and p38 MAPK activities
}

\author{
TONGHUI SHE ${ }^{1,2}$, XIAOYAN WANG ${ }^{1}$, YAPING GAN $^{2}$, DONG KUANG $^{1}$, \\ JUNQIU YUE $^{1}$, JUAN NI $^{1}$, XIA ZHAO $^{1}$ and GUOPING WANG ${ }^{1}$ \\ ${ }^{1}$ Institute of Pathology, Tongji Hospital, Tongji Medical College, Huazhong University of \\ Science and Technology, Wuhan 430030; ${ }^{2}$ Department of Pathology, School of Basic Medicine, \\ Hubei University of Science and Technology, Xianning 437100, P.R. China
}

Received June 6, 2012; Accepted July 23, 2012

DOI: $10.3892 / \mathrm{ijmm} .2012 .1125$

\begin{abstract}
Hyperglycemia in the acute phase of myocardial infarction (MI) is a marker of worse prognosis in both diabetic and non-diabetic patients; however, the role of hyperglycemia in the homing of cardiac stem cells (CSCs) to damaged myocardium post-MI and the possible mechanisms involved are not well understood. In this study, an MI model was induced in normoglycemic and hyperglycemic rats by left coronary artery ligation. Immunofluorescence was used to examine the migration of CSCs in vivo by injecting BrdU-labeled CSCs into the atrium-ventricle groove (AV-groove). Immunohistochemistry, western blot analysis and ELISA were carried out to detect the expression of stem cell factor (SCF) protein and RT-PCR was conducted for the expression of SCF mRNA. Phosphorylation of ERK1/2 and p38 MAPK was detected by western blot analysis. Afterwards, cardiac function was evaluated by hemodynamic measurement. On Day 5 post-MI, the accumulation of CSCs significantly increased in the peri-infarcted myocardium in normoglycemic rats, which led to an improvement in cardiac function 3 weeks after MI. However, the accumulation of CSCs markedly decreased in hyperglycemic rats, followed by the decline of cardiac function. SCF expression, followed with phosphorylation of ERK1/2 and p38 MAPK, were also significantly downregulated in the peri-infarcted myocardium in hyperglycemic rats compared to normoglycemic rats. Moreover, SCF expression and the migration of CSCs were blocked by either the MEK-specific inhibitor PD98059 or the
\end{abstract}

Correspondence to: Dr Xia Zhao or Professor Guoping Wang, Institute of Pathology, Tongji Hospital, Tongji Medical College, Huazhong University of Science and Technology, 1095 Jiefang Dadao, Wuhan 430030, P.R. China

E-mail: yespeony@126.com

E-mail: wanggp@hotmail.com

Key words: hyperglycemia, cardiac stem cell, stem cell factor, homing, mitogen-activated protein kinase p38 MAPK-selective inhibitor SB203580. The experiments in vitro confirmed that hyperglycemia decreased SCF expression via reduction in ERK1/2 and p38 MAPK activities and further inhibited the migration of CSCs. The results suggest that hyperglycemia suppresses CSC migration towards the ischemic area post-MI. This is possibly due to decreased myocardial SCF expression via reduction of ERK1/2 and p38 MAPK activities in hyperglycemic rats.

\section{Introduction}

Myocardial infarction (MI) remains an important cause of mortality by ultimately leading to heart failure or sudden cardiac death (1). Since massive cell death in the myocardium, particularly cardiomyocyte death, is the pivotal pathological change after MI, repairing injured tissues with healthy myocytes provides an attractive therapeutic strategy (2). Increasing evidence indicates that recruitment or direct injection of stem or progenitor cells could participate in the regeneration of heart tissue and improve cardiac function (3-5). The most appropriate cell source among various candidates may be c-kit ${ }^{+}$cardiac stem cells (CSCs) which reside mainly in the atrium-ventricle groove (AV-groove) (6). They could be attracted to injured myocardium and differentiated into cardiomyocytes, smooth muscle cells and vascular endothelium for reconstruction.

Together with other encouraging observations concerning CSCs, the mechanisms of migration and homing of CSCs have been partly revealed $(7,8)$. Stem cell factor (SCF), which belongs to the family of transmembrane-anchored growth factors with highly conserved cytoplasmic domains, is a critical chemotactic factor for mast and other c-kit ${ }^{+}$cells $(9,10)$. Several studies have indicated that $\mathrm{SCF} / \mathrm{c}-\mathrm{kit}$ signaling is involved in the migration of CSCs to peri-injured myocardium $(8,11,12)$. Da Silva et al $(13)$ considered that the activation of ERK1/2 and p38 MAPK induced by IL- $1 \beta$ could lead to SCF promoter activity, SCF mRNA and subsequently SCF protein formation by mediating phosphorylation of NF- $\mathrm{kB}$.

Diabetes is a metabolic syndrome with a cluster of common clinical disorders and is related to an increased 
risk for cardiovascular disease and accounts for $20-30 \%$ of hospital admissions for MI (14). It was reported that increases in glucose levels during the first $24 \mathrm{~h}$ of hospital stay were associated with higher mortality at 30 and 180 days, while decreases in glucose levels were associated with improved survival (15). Various studies have shown that hyperglycemia on hospital admission following acute coronary syndrome (ACS) was a major independent predictor of worse short- and long-term prognosis in both diabetic and non-diabetic patients (16-18). However, the role of hyperglycemia in the homing of CSCs to the damaged myocardium post-MI remains unclear. Thus, the aim of the present study was to investigate the role of hyperglycemia in the migration of CSCs and clarify the possible mechanisms involved.

\section{Materials and methods}

Animal models. Hyperglycemia was induced in male SpragueDawley rats (200-250 g) by a single intraperitoneal injection of streptozotocin (STZ, $65 \mathrm{mg} / \mathrm{kg}$ body weight; Sigma-Aldrich) which was dissolved in citrate buffer ( $\mathrm{pH} 4.5)$. The control group received an equivalent volume of citrate buffer injection alone. Seven days later, MI was conducted by ligation of the left anterior descending coronary artery (LAD) while the control group underwent a sham-operation. In the inhibition experiments, $0.5 \mathrm{mg} / \mathrm{kg}$ PD98059 (19), a specific inhibitor of MEK (upstream of ERK1/2), or $1.0 \mathrm{mg} / \mathrm{kg} \mathrm{SB203580} \mathrm{(20),} \mathrm{a}$ selective inhibitor of p38 MAPK, or an equivalent volume of vehicle was intraperitoneally administered $30 \mathrm{~min}$ prior to operation and once every day on Days 1-4 after MI. All procedures were performed in accordance with the Guidelines of the Hubei Council of Animal Care and approved by the Animal Use Subcommittee at the Huazhong University of Science and Technology, China.

Detection of blood glucose concentration. Blood samples were obtained from tail-tip bleedings, and blood glucose concentration was measured with a glucometer (Roche).

Isolation and culture of CSCs from the adult rat heart. The CSCs were isolated from the hearts of male Sprague-Dawley rats by a magnet-activated cell sorting (MACS) system (Dynal Biotech) as described previously $(6,8)$. Briefly, the heart was excised and the aorta was cannulated rapidly. The heart was then perfused with $\mathrm{Ca}^{2+}$-free Tyrode's solution for $10 \mathrm{~min}$, and digested by collagenase $(0.5 \mathrm{mg} / \mathrm{ml}$; Roche $)$ and trypsin $\left(0.05 \mathrm{mg} / \mathrm{ml}\right.$; Sigma-Aldrich) at $37^{\circ} \mathrm{C}$ for $30 \mathrm{~min}$. Next, the heart tissue was chopped, and the cell suspension was filtered with a strainer (Becton Dickson). Afterwards, cells were incubated with a rabbit anti-c-kit antibody (1:150; Santa Cruz Biotechnology, Inc.) and separated by using sheep anti-rabbit immunomagnetic microbeads (Dynal Biotech). Small round cells, containing most of the c-kit ${ }^{+}$population, were separated. These c-kit ${ }^{+}$CSCs were cultured for 3-5 days with Dulbecco's modified Eagle's medium/Ham's Nutrient Mixture F12 (1:1) (DMEM/F12; Sigma-Aldrich) containing $15 \%$ fetal bovine serum (FBS; Gibco), basic fibroblast growth factor (bFGF, $10 \mathrm{ng} / \mathrm{ml}$; Sigma-Aldrich), epidermal growth factor (EGF, $20 \mathrm{ng} / \mathrm{ml}$; Sigma-Aldrich) and leucocyte inhibitory factor (LIF, $10 \mathrm{ng} / \mathrm{ml}$;
Sigma-Aldrich) at $37^{\circ} \mathrm{C}$. After recovery, these CSCs were used for subsequent experiments.

Isolation and culture of neonatal rat cardiomyocytes. Ventricular cardiomyocytes were isolated from neonatal Sprague-Dawley rats and submitted to primary culture as reported previously (21). After recovery, these cells were incubated in FBS-free DMEM with glucose (5.5 or $25 \mathrm{mM})$, glucose $(5.5$ or $25 \mathrm{mM})+\mathrm{IL}-1 \beta(1 \mathrm{ng} / \mathrm{ml}$; Sigma-Aldrich), glucose $(5.5 \mathrm{mM})+\mathrm{IL}-1 \beta+\mathrm{PD} 98059(10 \mu \mathrm{M})$, or glucose $(5.5 \mathrm{mM})+\mathrm{IL}-1 \beta+\mathrm{SB} 203580(10 \mu \mathrm{M})$ for $12 \mathrm{~h}$. The supernatants of cultured cardiomyocytes were used as conditioned media (CM). SCF mRNA in cells was detected by RT-PCR, and SCF protein was analyzed by ELISA.

$R T-P C R$. Total RNA was extracted from peri-infarcted myocardium of the left ventricle and cultured cardiomyocytes with TRIzol reagent (Invitrogen Life Technologies). RT-PCR was carried out using the pairs of primers as following for semi-quantitative assessment. SCF: sense, 5'-TGTTTTG CCTAGTCATTGTTG-3' and anti-sense, 5'-TGTCATTCCTA AGGGAACTG-3', yielding a 404 bp product; $\beta$-actin: sense, 5'-CGTTGACATCCGTAAAGA-3' and anti-sense, 5'-AGCC ACCAATCCACACAG-3', yielding a 173 bp product. The products of PCR were separated by $1.5 \%$ agarose gel electrophoresis and visualized under UV using a gel documentation system (Bio-Rad). $\beta$-actin was used as an internal standard to verify equal PCR product loading for each experiment.

Western blot analysis. Tissue samples were homogenized and separated by SDS polyacrylamide gel (12.5\%) electrophoresis followed by electrophoretic transfer of proteins from the gel to nitrocellulose membranes (Bio-Rad). The membranes were probed with the following primary antibodies: rabbit antiSCF, mouse anti- $\beta$-actin, mouse anti-P-p38, rabbit anti-p38, mouse anti-P-ERK, or rabbit anti-ERK1/2 (1:600; all from Santa Cruz Bioetchnology, Inc.) overnight at $4^{\circ} \mathrm{C}$. Bands were visualized by using corresponding horseradish peroxidase (HRP)-conjugated anti-biotin antibody and enhanced chemiluminescence reagents (Pierce Biotechnology, Inc.).

Immunohistochemical staining. On Day 5 after MI, heart slices from the peri-injured myocardium were prepared for immunohistochemical staining. Slices were incubated with rabbit polyclonal antibodies (1:100; PeproTech) against rat $\mathrm{SCF}$ overnight at $4^{\circ} \mathrm{C}$ (for negative control studies, the antibodies were substituted by phosphate-buffered saline). Endogenous peroxidase was blocked by $0.3 \% \mathrm{H}_{2} \mathrm{O}_{2}$ for $20 \mathrm{~min}$ at room temperature and the biotin-conjugated anti-rabbit immunoglobulin (1:200; Dako) was used as the secondary antibody. After incubation with streptavidin peroxidase, visualization of peroxidase localization was performed using diaminobenzidine-hydrogen peroxide $\left(\mathrm{DAB}-\mathrm{H}_{2} \mathrm{O}_{2}\right)$ substrate to give a brown color.

Immunofluorescence. To assess the migration of CSCs in vivo after MI, cultured CSCs were labeled with 5-bromo-2'-deoxyuridine (BrdU; Sigma-Aldrich) as described previously (22). The BrdU-labeled CSCs $\left(1 \times 10^{6}\right)$ were injected into the AV-groove of the rat heart followed by LAD ligation or 
A
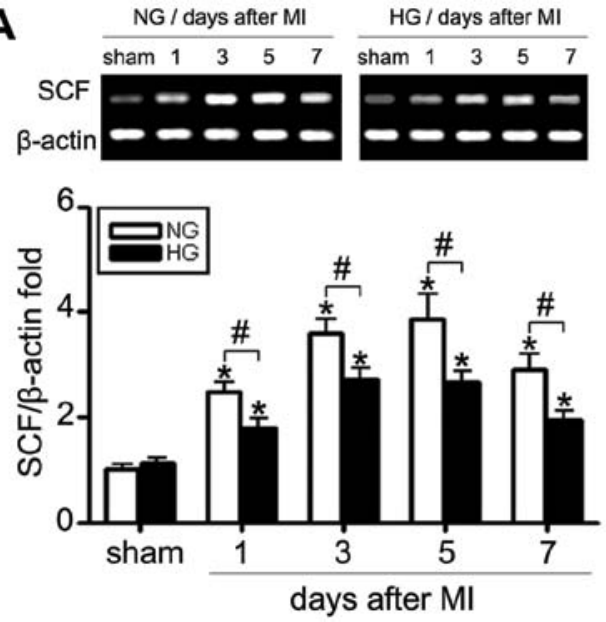

B

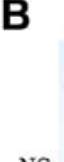

MI

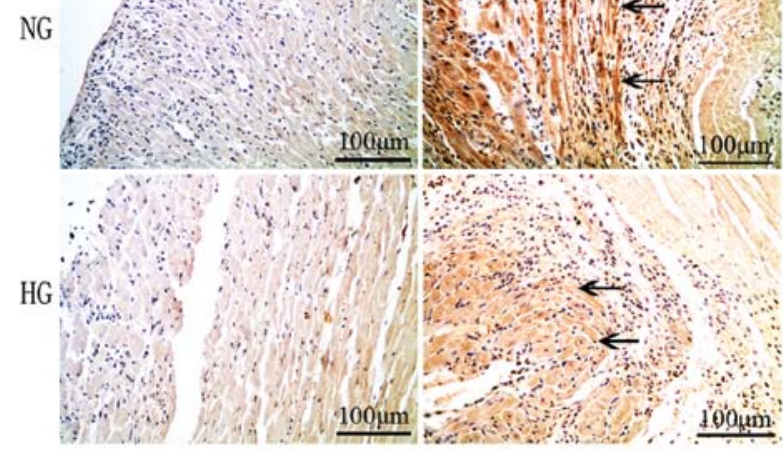

Figure 1. SCF expression in the peri-infarcted myocardium of rats. (A) SCF mRNA level analyzed by RT-PCR in NG and HG groups on Day 1, 3, 5 and 7 after MI compared with the sham-operated group. (B) SCF protein expression detected by immunohistochemical staining in sham and MI groups on Day 5 after the operation ( $€$ indicates peri-infarcted cardiomyocytes with SCF expression). NG, normoglycemia; HG, hyperglycemia. n=5-7/group. Results were depicted as means \pm SEM. ${ }^{*} \mathrm{P}<0.05$ vs. Sham group; ${ }^{\#} \mathrm{P}<0.05$ vs. normoglycemic MI group.

sham operation. On Day 5 post-MI, histological examination was performed to visualize the localization of the BrdUlabeled CSCs using mouse anti-BrdU antibody (1:150; Zymed) and TRITC-conjugated goat anti-mouse IgG antibody. The numbers of $\mathrm{BrdU}^{+}$cells homing to the peri-infarcted area were counted in 5 randomly selected sections per heart, and for each section 10 fields were randomly chosen by high-power fields.

Hemodynamic measurement. Three weeks after LAD ligation or sham operation, rats were anesthetized again. The right carotid artery was cannulated with a Millar Micro-Tip pressure transducer catheter. After obtaining the arterial blood pressure and heart rate, the catheter was advanced into the left ventricle (LV) to measure the systolic and end-diastolic pressures as well as the rate of pressure development $\left(+\mathrm{dP} / \mathrm{dt}_{\max }\right)$ and rate of relaxation $\left(-\mathrm{dP} / \mathrm{dt}_{\min }\right)$ of the $\mathrm{LV}$.

ELISA. A sensitive ELISA procedure was used to quantify immunoreactive SCF released into the supernatant of the cultured cardiomyocytes. The ELISA was performed according to the instructions provided by the manufacturer (R\&D systems). A polystyrene microplate (96 wells) was coated with a rabbit polyclonal anti-SCF antibody, and recombinant rat SCF was used as the standard.

Chemotaxis assay. Chemotaxis experiments were performed using a 48-well chemotaxis chamber technique (Neuro Probe) as previously described (23). Briefly, $25 \mu \mathrm{l}$ of DMEM + glucose (5.5 mM), virus conditioned media (CM), or CM + SCF-Ab (rabbit anti-rat SCF, 1:600; Santa Cruz Biotechnology, Inc.) was placed in the lower chamber. A polycarbonate membrane with a $5-\mu \mathrm{m}$ pore size separated the upper and lower chamber. CSCs resuspended in DMEM $(50 \mu 1)$ were placed in each well of the upper chamber. The chamber was then incubated for $3 \mathrm{~h}$ at $37^{\circ} \mathrm{C}$ in a humidified atmosphere with $5 \% \mathrm{CO}_{2}$ and then disassembled. The membrane was removed and scraped to remove non-migrating CSCs from the upper surface. Then the membrane was fixed and stained. The numbers of CSCs that had migrated to the lower surface of the membrane were counted in ten random high-power fields (HPFs) by light microscopy, and a chemotactic index (CI) was calculated to express stimulated migration. Each assay was performed in triplicate wells.

$$
\mathrm{CI}=\frac{\text { Stimulated migration (Number of CSCs/HPF) }}{\text { Random migration (Number of CSCs/HPF) }}
$$

Statistical analysis. All data are expressed as means \pm SEM. For analysis of differences between 2 groups, the Student's t-test was performed. For multiple groups, ANOVA was carried out followed by the Student-Newman-Keuls test. The level of statistical significance was set at $\mathrm{P}<0.05$.

\section{Results}

STZ induction of hyperglycemia. Blood glucose concentration was measured to validate whether STZ induced hyperglycemia as expected. Seven days after STZ administration, the blood glucose concentration reached $20.33 \pm 1.84 \mathrm{mM}$, significantly higher than that of $6.72 \pm 0.35 \mathrm{mM}$ in the control group $(\mathrm{P}<0.01)$.

Effect of hyperglycemia on SCF expression in the periinfarcted myocardium. To investigate whether hyperglycemia influences SCF expression which subsequently affects CSC homing, SCF mRNA and protein in the peri-infarcted myocardium were analyzed. RT-PCR revealed that the SCF mRNA level increased significantly in the peri-infarcted myocardium on Day 1,3,5 and 7 after MI in the normoglycemic and hyperglycemic rats (Fig. 1A). Immunohistochemical staining and western blot analysis also revealed that SCF protein expression dramatically increased in the peri-infarcted myocardium on Day 5 after MI, which was in line with the change in SCF mRNA (Figs. 1B and 3A). However, the increase in SCF mRNA and protein was significantly attenuated in the hyperglycemic group compared to the normoglycemic group. 

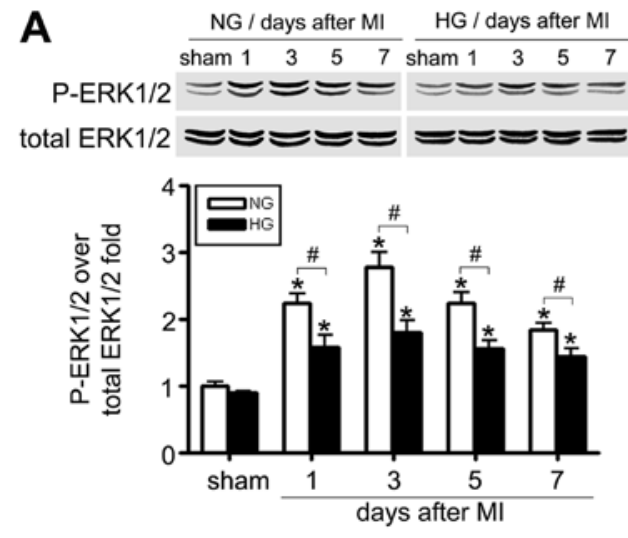

B
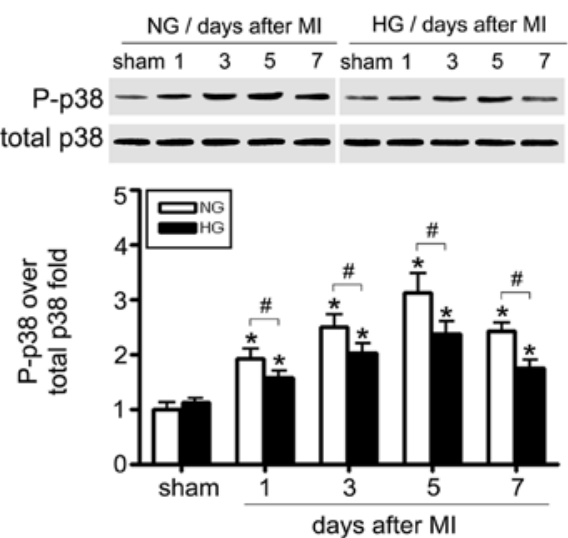

Figure 2. ERK1/2 and p38 MAPK activation in the peri-infarcted myocardium were analyzed by western blotting. (A) Phosphorylation of ERK1/2 (P-ERK1/2) over total ERK1/2 (total-ERK1/2) was measured on Day 1,3,5 or 7 after MI compared with the sham-operated group. (B) Phosphorylation of p38 MAPK (P-p38) over total p38 MAPK (total-p38) was measured on Day 1, 3, 5 or 7 after MI compared with the sham-operated group. NG, normoglycemia; HG, hyperglycemia. $n=5-7 /$ group. Results were depicted as means \pm SEM. ${ }^{*} \mathrm{P}<0.05$ vs. the sham group; ${ }^{\prime \prime} \mathrm{P}<0.05$ vs. normoglycemic MI group.
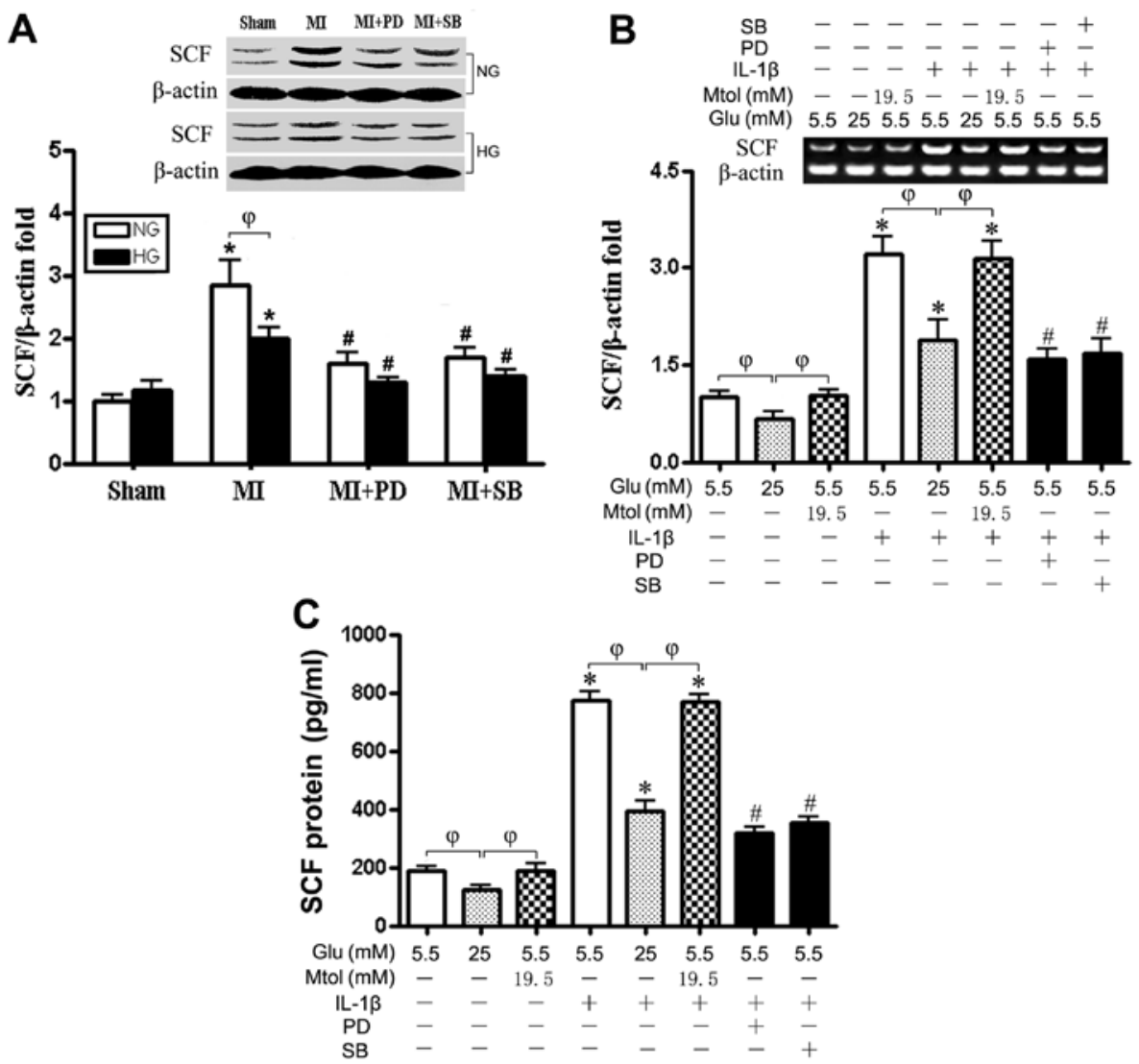

Figure 3. Effect of PD98059 or SB203580 on SCF expression in the peri-infarcted myocardium. PD98059 or SB203580 was administered as the inhibitor to investigate the relationship between ERK1/2 or p38 activation and SCF expression. IL-1 $\beta$ was used as the stimulator to induce SCF expression. Mtol (19.5 mM) was used as the osmotic control. (A) SCF protein in the peri-infarcted myocardium was analyzed on Day 5 after MI by western blotting. (B) SCF mRNA level in cultured cardiomyocytes was analyzed by RT-PCR. (C) SCF protein in the conditional medium of cultured cardiomyocytes was analyzed by ELISA. NG, normoglycemia; HG, hyperglycemia; PD, PD98059; SB, SB203580; Mtol, mannitol; Glu, glucose. $n=5-7 /$ group. Results were depicted as means \pm SEM. "P<0.05 vs. sham group in A or vs. IL-1 $1 \beta$-free groups in B and C; ${ }^{*} \mathrm{P}<0.05$ vs. MI groups in A or vs. Glu $(5.5 \mathrm{mM})+\mathrm{IL}-1 \beta$ groups in $\mathrm{B}$ and $\mathrm{C} ;{ }^{\phi} \mathrm{P}<0.05$ between two groups.

Effect of hyperglycemia on the phosphorylation of ERK1/2 and $p 38$ MAPK in the peri-infarcted myocardium. To understand whether ERK1/2 and p38 MAPK are involved in the inhibition of SCF expression, western blot analysis was performed to detect the levels of phosphorylated or total ERK1/2 and p38 MAPK proteins in the peri-infarcted myocardium. Results showed that the phosphorylation of ERK1/2 (Fig. 2A) and p38 MAPK (Fig. 2B) in the periinfarcted regions were obviously upregulated on Day 1,3 , 5 and 7 after MI in the normoglycemic and hyperglycemic 
A
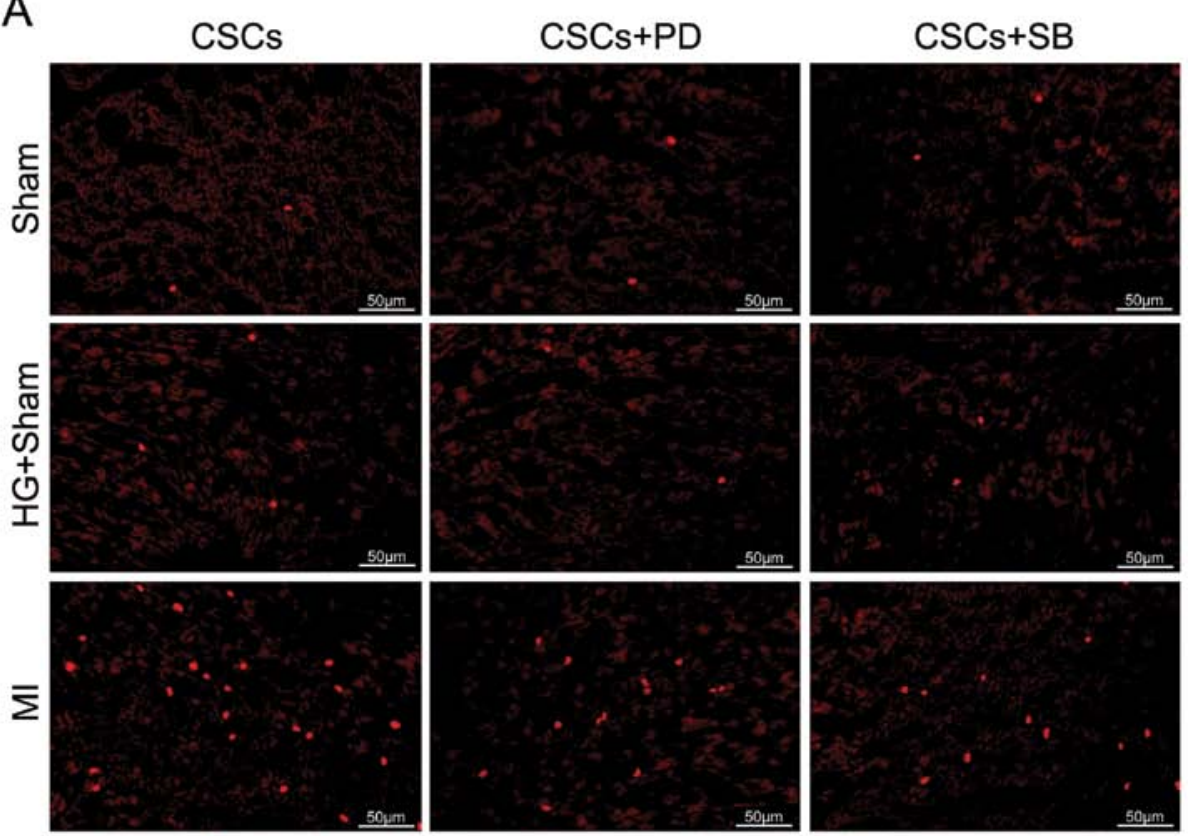

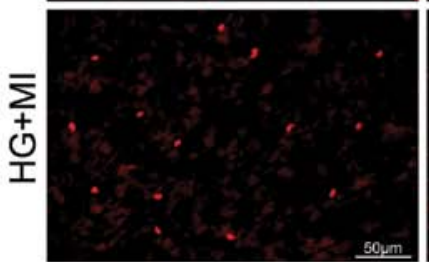

B

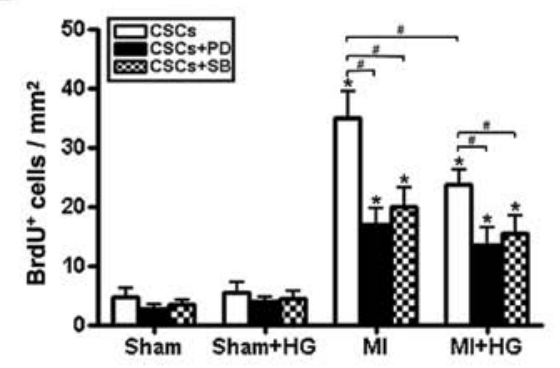

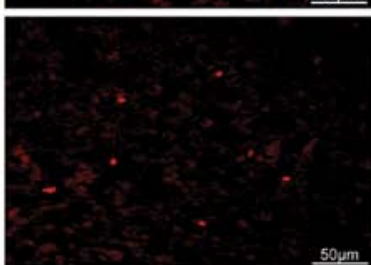

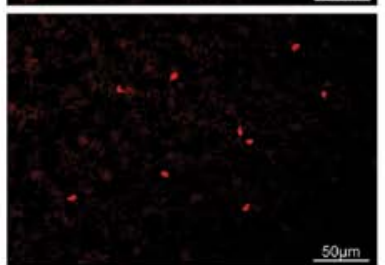

C

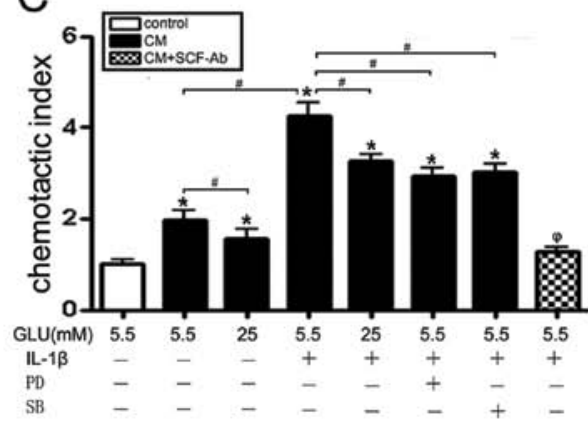

Figure 4. BrdU ${ }^{+}$CSC accumulation in the peri-infarcted myocardium. CSCs labeled with BrdU were injected into the AV-groove prior to sham or MI operation. On Day 5 after the operation, BrdU + CSCs in the peri-infarcted myocardium were detected by TRITC-conjugated goat anti-mouse IgG. (A) Original images of BrdU + CSC accumulation in the peri-infarcted myocardium. (B) Calculation of BrdU $+\mathrm{CSCs} / \mathrm{mm}^{2}$ in the peri-infarcted myocardium (5-7 rats/ group). At least 5 sections per heart were selected and 10 fields per section were randomly chosen (x40 objective). (C) Chemotactic index of CSC migration in vitro detected by Boyden chamber (data from five independent experiments). HG, hyperglycemia; CM, conditioned medium; PD, PD98059; SB, SB203580. Results were depicted as means \pm SEM. ${ }^{*} \mathrm{P}<0.05$ vs. sham groups in $\mathrm{B}$ or vs. control group in $\mathrm{C}$; ${ }^{~} \mathrm{P}<0.05$ between two groups; ${ }^{\phi} \mathrm{P}<0.05$ vs. $\mathrm{CM}$ groups.

groups, but the levels of regulation in the hyperglycemic group were attenuated compared to the normoglycemic group. Total ERK1/2 and p38 MAPK protein expression showed no obvious differences in the normoglycemic and hyperglycemic groups. This suggests that the increase in SCF in the periinfarcted myocardium may be associated with the activation of ERK1/2 and p38 MAPK, which may be attenuated by hyperglycemia.

Effect of PD98059 or SB203580 on SCF expression. To elucidate the relationship between the increase in SCF expression and the upregulation of ERK1/2 and p38 MAPK activities, inhibitors of ERK1/2 (PD98059) and p38 MAPK (SB203580) were administered $30 \mathrm{~min}$ prior to operation and once every day on Days 1-4 after MI. Western blot analysis revealed that SCF protein significantly increased in the peri-infarcted myocardium on Day 5 after MI, but the increase was significantly attenuated by administration of PD98059 or SB203580, which was similar to the inhibiting effect of hyperglycemia (Fig. 3A). Meanwhile, in vitro experiments were performed in cultured cardiomyocytes. RT-PCR and ELISA showed that a high glucose level $(25 \mathrm{mM})$ markedly decreased the SCF expression compared to a normal glucose level $(5.5 \mathrm{mM})$ and osmotic control (5.5 mM glucose $+19.5 \mathrm{mM}$ mannitol). After stimulation by IL-1 $\beta$, SCF expression was greatly increased. However, the increase was significantly downregulated by PD98059 or SB203580, which was similar to the effect of high glucose (Fig. 3B and C). All of these results suggest that 


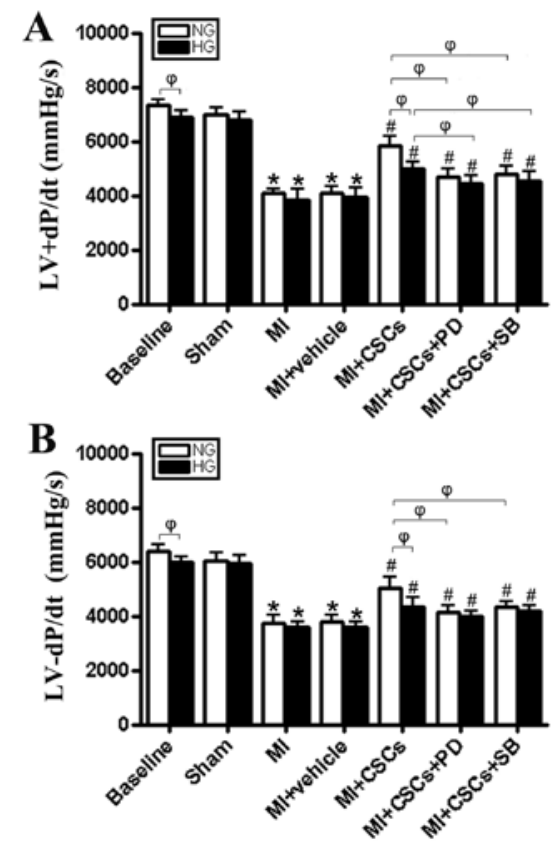

Figure 5. Cardiac function was measured at Day 21 after MI. Changes in LV $+\mathrm{dP}^{-\mathrm{dt}_{\max }}$ and $-\mathrm{dP} / \mathrm{dt}_{\min }$ are shown in (A) and (B), respectively. NG, normoglycemia; HG, hyperglycemia; PD, PD98059; SB, SB203580. n=5-7/group. Results were depicted as means $\pm \mathrm{SEM}$. " $\mathrm{P}<0.05$ vs. sham groups; ${ }^{\text {}} \mathrm{P}<0.05$ vs. MI groups and MI + vehicle groups; ${ }^{\phi} \mathrm{P}<0.05$ between two groups.

hyperglycemia inhibits SCF expression in the peri-infarcted myocardium via downregulation of ERK1/2 and p38 MAPK activities.

Effect of hyperglycemia on CSC migration. To investigate whether the upregulation of SCF leads to a higher accumulation of CSCs in the peri-infarcted region after MI, CSC migration in vivo was performed by injection of BrdU-labeled CSCs into the AV-groove followed by coronary ligation. As shown in Fig. 4A and B, more CSCs were attracted to the peri-infarcted myocardium on Day 5 after MI compared with the sham-operated group. However, in the hyperglycemic rats, CSC homing was markedly inhibited, which was similar to the effect of PD98059 or SB203580 administration in normoglycemic rats. In vitro chemotaxis experiments were also carried out to quantitatively evaluate CSC migration under different conditions. As shown in Fig. 4C, compared with the control group, the average number of migrated CSCs increased significantly in the conditioned medium groups. Adding high glucose, PD98059, SB203580 or an SCF antibody partially or totally inhibited the migration. These results imply that hyperglycemia suppresses CSC homing to the peri-infarcted myocardium through attenuation of SCF expression.

Effect of hyperglycemia on cardiac function. To ascertain whether CSC homing to the peri-infarct myocardium correlates with a change in cardiac function, cardiac function was evaluated on Day 21 after MI by hemodynamic measurement. As expected, the results of $+\mathrm{dP} / \mathrm{dt}_{\max }$ (Fig. 5A) and $-\mathrm{dP} / \mathrm{dt}_{\min }$ (Fig. 5B) indicated that cardiac function was notably aggra- vated after induction of MI. However, AV-groove injection of CSCs resulted in obvious improvement in cardiac function, and this improvement was partially blocked by administration of PD98059 or SB203580. In the hyperglycemic rats, cardiac function was much aggravated after MI compared with the normoglycemic rats. The recovery of cardiac function after $\mathrm{AV}$-groove injection of CSCs was also observed in the hyperglycemic rats, but the levels of $\mathrm{LV}+\mathrm{dP} / \mathrm{dt}_{\max }$ and $-\mathrm{dP}^{\mathrm{d} \mathrm{dt}_{\min }}$ were significantly lower than levels in the normoglycemic rats. These results imply that hyperglycemia inhibits the recovery of cardiac function through inhibition of CSC homing after MI.

\section{Discussion}

The incidence of diabetes is rising dramatically throughout the world. Diabetic patients have a high incidence of acute coronary syndrome (ACS) and account for 20-30\% of hospital admissions for MI (14). Although advances in treatment have significantly improved the prognosis of ACS in recent years, diabetic patients still have a worse prognosis than non-diabetic patients. Hyperglycemia in the acute phase of MI is a marker of worse short- and long-term prognosis, in both diabetic and non-diabetic patients (16-18). A large study of 141,860 elderly patients hospitalized with MI showed that the level of hyperglycemia at admission was associated with significantly higher mortality, depending on the degree of hyperglycemia (16). Higher blood glucose levels were found to be associated with a significant increase in 30-day mortality in nondiabetic patients with MI. However, it remains unclear how hyperglycemia affects MI and the mechanisms involved.

The adult heart is considered to be a terminally differentiated organ. Any attempt to replace lost myocytes using cellular therapy would require the introduction of exogenous cells. However, Beltrami et al (6) reported that the adult heart contains CSCs, which are multipotent and could participate in myocardial regeneration. Recently, at least three CSCs or cardiac progenitor cell pools were reported in different species. Distinguished by definite marker proteins, the major three populations of CSCs were c-kit ${ }^{+}$cells (6), cells from the side population (24) and cardioblasts expressing islet-1 (25). Previous studies revealed that the injured myocardium could attract CSC homing to repair the damaged region $(8,11,12)$. But it remains unknown whether hyperglycemia, which usually acts as a risk factor in heart diseases, influences CSC homing after MI.

Results from the present study demonstrated that less CSCs migrated to the peri-infarcted region in hyperglycemic rats compared with normoglycemic rats. This implies that hyperglycemia inhibits CSC homing and attenuates the recovery of cardiac function after MI. However, the mechanisms involved require further investigation.

Fazel et al (26) found that stem cell-mediated myocardial repair depended on the activation of SCF, which plays a crucial role in chemotaxis and homing of $\mathrm{c}^{-\mathrm{kit}^{+}}$stem cells. Lutz et al (27) reported that administration of SCF could promote lin $/ \mathrm{c}-\mathrm{kit}^{+} \mathrm{BMSC}$ migration to injured myocardium. Meloni et al (11) also found that nerve growth factor overexpression increased SCF expression, which translated in the higher myocardial abundance of c-kit ${ }^{+}$stem cells. Based on 
these findings, we hypothesized that hyperglycemia affects CSC homing by regulating the expression of SCF in the periinfarcted myocardium. Results from the present study showed that SCF mRNA and protein expression in the peri-infarcted myocardium was upregulated post-MI in normoglycemic rats, which was associated with more CSCs homing to the peri-infarcted area and greater improvement in cardiac function. However, the upregulation of SCF mRNA and protein was obviously inhibited in hyperglycemic rats compared to normoglycemic rats, which, in turn, led to less CSC accumulation in the peri-infarcted myocardium and significant attenuation of the cardiac function. Chemotactic experiments in vitro confirmed these results. The present study indicated that hyperglycemia inhibited CSC homing after MI via downregulation of SCF expression. In this process, some important factors might be involved in the signal transduction mechanism underlying SCF expression.

It is well known that mitogen-activated protein kinases (MAPKs) compose a family of serine/threonine kinases that regulate the diversity of cellular activities. MAPKs mainly include extracellular signal-regulated kinases 1 or 2 (ERK1/2), c-Jun NH2-terminal kinases (JNKs) and p38 MAPK. Besides being structurally related, the MAPK family members are generally activated via multistep phosphorylation cascades $(28,29)$. Previous studies demonstrated that ERK1/2 and p38 MAPK play a key role in cytokine gene expression $(13,30)$. The role of MAPKs in pathological cardiac remodeling has been investigated in several studies. After experimental MI, ERK1/2, JNK1/2 and p38 MAPK were found to be activated in both ischemic myocardium and unaffected portions of the left ventricle in mice and rats $(31,32)$. In the process of cardiac remodeling after MI, the activation of the p38 MAPK and JNK $1 / 2$ cascades promoted fibrosis in the infarct area and unaffected myocardium, but the role of the ERK1/2 cascade is not well known $(33,34)$. Hue et al $(35)$ reported that IL-18 enhanced the SCF production of melanoma cells by regulating ROI and p38 MAPK activities but not ERK1/2. Takata et al (36) reported that high glucose induced transactivation of the $\alpha 2$-HS glycoprotein gene through the ERK1/2 signaling pathway. Ku et al (37) suggested that hyperglycemia could cause systolic dysfunction in cardiomyocytes through enhancing MEK/ERK-induced GATA-4 phosphorylation. In the present study, results showed that the phosphorylation of ERK1/2 and p38 MAPK in the peri-infarcted regions was obviously upregulated on Day 1, 3, 5, 7 after MI in normoglycemic and hyperglycemic groups, but the levels of regulation in the hyperglycemic group was attenuated compared to the normoglycemic group. After administration of PD98059 or SB203580, the increase of SCF protein in the peri-infarcted area was downregulated, followed by less CSC accumulation in the peri-infarcted myocardium and significant attenuation of the cardiac function. An in vitro experiment also showed that SCF mRNA and protein in cardiomyocytes could be downregulated by PD98059 or SB203580. Chemotactic experiments confirmed that CSC migration was inhibited by PD98059 or SB203580. All these results indicate that activation of ERK1/2 and p38 MAPK signaling contributed to SCF expression, and hyperglycemia inhibited SCF expression partially through downregulation of ERK1/2 and p38 MAPK activities.
In summary, hyperglycemia suppressed CSC migration towards the ischemic area post-MI. This was possibly due to decreased myocardial SCF expression via reduction in ERK1/2 and p38 MAPK activities in hyperglycemic rats. Further understanding of CSC homing in hyperglycemia may contribute to the development of a novel strategy for cardiac regenerative therapy.

\section{Acknowledgements}

This study was supported by the National Nature Science Foundation of China $(30470710,30971153)$ and a research grant from the Trans-Century Training Program Foundation for Talents by the State Education Commission (NCET-04-0711).

\section{References}

1. Rosamond W, Flegal K, Furie K, Go A, Greenlund K, Haase N, Hailpern SM, Ho M, Howard V, Kissela B, Kittner S, LloydJones D, McDermott M, Meigs J, Moy C, Nichol G, O'Donnell C, Roger V, Sorlie P, Steinberger J, Thom T, Wilson M and Hong Y: Heart disease and stroke statistics - 2008 update: a report from the American Heart Association Statistics Committee and Stroke Statistics Subcommittee. Circulation 117: e25-e146, 2008.

2. Evans SM, Mummery C and Doevendans PA: Progenitor cells for cardiac repair. Semin Cell Dev Biol 18: 153-160, 2007.

3. Kajstura J, Urbanek K, Rota M, Bearzi C, Hosoda T, Bolli R, Anversa $\mathrm{P}$ and Leri A: Cardiac stem cells and myocardial disease. J Mol Cell Cardiol 45: 505-513, 2008.

4. Lunde $\mathrm{K}$ and Aakhus S: Cell therapy in acute myocardial infarction: measures of efficacy. Heart 94: 969-970, 2008.

5. Yang L, Soonpaa MH, Adler ED, Roepke TK, Kattman SJ, Kennedy M, Henckaerts E, Bonham K, Abbott GW, Linden RM, Field LJ and Keller GM: Human cardiovascular progenitor cells develop from a $\mathrm{KDR}^{+}$embryonic-stem-cell-derived population. Nature 453: 524-528, 2008

6. Beltrami AP, Barlucchi L, Torella D, Baker M, Limana F, Chimenti S, Kasahara H, Rota M, Musso E, Urbanek K, Leri A, Kajstura J, Nadal-Ginard B and Anversa P: Adult cardiac stem cells are multipotent and support myocardial regeneration. Cell 114: 763-776, 2003.

7. Fransioli J, Bailey B, Gude NA, Cottage CT, Muraski JA, Emmanuel G, Wu W, Alvarez R, Rubio M, Ottolenghi S, Schaefer E and Sussman MA: Evolution of the c-kit-positive cell response to pathological challenge in the myocardium. Stem Cells 26: 1315-1324, 2008.

8. Kuang D, Zhao X, Xiao GX, Ni J, Feng YM, Wu RL and Wang GP: Stem cell factor/c-kit signaling mediated cardiac stem cell migration via activation of p38 MAPK. Basic Res Cardiol 103: 265-273, 2008.

9. Heissig B, Hattori K, Dias S, Friedrich M, Ferris B, Hackett NR, Crystal RG, Besmer P, Lyden D, Moore MA, Werb Z and Rafii S: Recruitment of stem and progenitor cells from the bone marrow niche requires MMP-9 mediated release of kit-ligand. Cell 109: 625-637, 2002.

10. Vandervelde S, van Luyn MJ, Tio RA and Harmsen MC: Signaling factors in stem cell-mediated repair of infarcted myocardium. J Mol Cell Cardiol 39: 363-376, 2005.

11. Meloni M, Caporali A, Graiani G, Lagrasta C, Katare R, Van Linthout S, Spillmann F, Campesi I, Madeddu P, Quaini F and Emanueli C: Nerve growth factor promotes cardiac repair following myocardial infarction. Circ Res 106: 1275-1284, 2010.

12. Xiang FL, Lu X, Hammoud L, Zhu P, Chidiac P, Robbins J and Feng QP: Cardiomyocyte-specific overexpression of human stem cell factor improves cardiac function and survival after myocardial infarction in mice. Circulation 120: 1065-1074, 2009.

13. Da Silva CA, Heilbock C, Kassel O and Frossard N: Transcription of stem cell factor (SCF) is potentiated by glucocorticoids and interleukin-1beta through concerted regulation of a GRE-like and an NF-kappaB response element. FASEB J 17: 2334-2336, 2003. 
14. Bartnik M, Rydén L, Ferrari R, Malmberg K, Pyörälä K, Simoons M, Standl E, Soler-Soler J and Ohrvik J; Euro Heart Survey Investigators: The prevalence of abnormal glucose regulation in patients with coronary artery disease across Europe The Euro Heart Survey on diabetes and the heart. Eur Heart J 25: 1880-1890, 2004.

15. Goyal A, Mahaffey KW, Garg J, Nicolau JC, Hochman JS, Weaver WD, Theroux P, Oliveira GB, Todaro TG, Mojcik CF, Armstrong PW and Granger CB: Prognostic significance of the change in glucose level in the first $24 \mathrm{~h}$ after acute myocardial infarction: results from the CARDINAL study. Eur Heart J 27: 1289-1297, 2006.

16. Kosiborod M, Rathore SS, Inzucchi SE, Masoudi FA, Wang Y Havranek EP and Krumholz HM: Admission glucose and mortality in elderly patients hospitalized with acute myocardial infarction: implications for patients with and without recognized diabetes. Circulation 111: 3078-3086, 2005.

17. Deedwania P, Kosiborod M, Barrett E, Ceriello A, Isley W, Mazzone T and Raskin P: Hyperglycemia and acute coronary syndrome: a scientific statement from the American Heart Association Diabetes Committee of the Council on Nutrition, Physical Activity, and Metabolism. Circulation 117: 1610-1619, 2008.

18. Opie LH: Metabolic management of acute myocardial infarction comes to the fore and extends beyond control of hyperglycemia. Circulation 117: 2172-2177, 2008.

19. Carroll R and Yellon DM: Delayed cardioprotection in a human cardiomyocyte-derived cell line: the role of adenosine, p38MAP kinase and mitochondrial KATP. Basic Res Cardiol 95: 243-249, 2000.

20. Fryer RM, Hsu AK and Gross GJ: ERK and p38 MAP kinase activation are components of opioid-induced delayed cardioprotection. Basic Res Cardiol 96: 136-142, 2001.

21. Yue TL, Wang C, Romanic AM, Kikly K, Keller P, DeWolf WE Jr., Hart TK, Thomas HC, Storer B, Gu JL, Wang X and Feuerstein GZ: Staurosporine-induced apoptosis in cardiomyocytes: A potential role of caspase-3. J Mol Cell Cardiol 30: 495-507, 1998.

22. Barbash IM, Chouraqui P, Baron J, Feinberg MS, Etzion S, Tessone A, Miller L, Guetta E, Zipori D, Kedes LH, Kloner RA and Leor J: Systemic delivery of bone marrow-derived mesenchymal stem cells to the infarcted myocardium: feasibility, cell migration, and body distribution. Circulation 108: 863-868, 2003.

23. Song ZH and Zhong M: CB1 cannabinoid receptor-mediated cell migration. J Pharmacol Exp Ther 294: 204-209, 2000.

24. Hierlihy AM, Seale P, Lobe CG, Rudnicki MA and Megeney LA The post-natal heart contains a myocardial stem cell population. FEBS Lett 530: 239-243, 2002

25. Laugwitz KL, Moretti A, Lam J, Gruber P, Chen Y, Woodard S, Lin LZ, Cai CL, Lu MM, Reth M, Platoshyn O, Yuan JX, Evans $S$ and Chien KR: Postnatal is $11^{+}$cardioblasts enter fully differentiated cardiomyocyte lineages. Nature 433: 647-653, 2005 .
26. Fazel S, Chen L, Weisel RD, Angoulvant D, Seneviratne C, Fazel A, Cheung P, Lam J, Fedak PW, Yau TM and Li RK: Cell transplantation preserves cardiac function after infarction by infarct stabilization: augmentation by stem cell factor. J Thorac Cardiovasc Surg 130: 1310, 2005.

27. Lutz M, Rosenberg M, Kiessling F, Eckstein V, Heger T, Krebs J, Ho AD, Katus HA and Frey N: Local injection of stem cell factor (SCF) improves myocardial homing of systemically delivered c-kit ${ }^{+}$bone marrow-derived stem cells. Cardiovasc Res 77: 143-150, 2008.

28. Nishida E and Gotoh Y: The MAP kinase cascade is essential for diverse signal transduction pathways. Trends Biochem Sci 18: 128-131, 1993.

29. Sanchez I, Hughes RT, Mayer BJ, Yee K, Woodgett JR, Avruch J, Kyriakis JM and Zon LI: Role of SAPK/ERK kinase-1 in the stress-activated pathway regulating transcription factor c-Jun. Nature 372: 794-798, 1994.

30. Reber L, Vermeulen L, Haegeman G and Frossard N: Ser276 phosphorylation of NF-kB p65 by MSK1 controls SCF expression in inflammation. PLoS One 4: e4393, 2009.

31. Ren J, Zhang S, Kovacs A, Wang Y and Muslin AJ: Role of p38alpha MAPK in cardiac apoptosis and remodeling after myocardial infarction. J Mol Cell Cardiol 38: 617-623, 2005.

32. Yoshida K, Yoshiyama M, Omura T, Nakamura Y, Kim S, Takeuchi K, Iwao H and Yoshikawa J: Activation of mitogenactivated protein kinases in the non-ischemic myocardium of an acute myocardial infarction in rats. Jpn Circ J 65: 808-814, 2001.

33. Frantz S, Behr T, Hu K, Fraccarollo D, Strotmann J, Goldberg E, Ertl G, Angermann CE and Bauersachs J: Role of p38 mitogenactivated protein kinase in cardiac remodelling. Br J Pharmacol 150: 130-135, 2007

34. Matsumoto-Ida M, Takimoto Y, Aoyama T, Akao M, Takeda T and Kita T: Activation of TGF-beta1-TAK1-p38 MAPK pathway in spared cardiomyocytes is involved in left ventricular remodeling after myocardial infarction in rats. Am J Physiol Heart Circ Physiol 290: H709-H715, 2006.

35. Hue J, Kim A, Song H, Choi I, Park H, Kim T, Lee WJ, Kang H and Cho D: IL-18 enhances SCF production of melanoma cells by regulating ROI and p38 MAPK activity. Immunol Lett 96: 211-217, 2005 .

36. Takata H, Ikeda Y, Suehiro T, Ishibashi A, Inoue M, Kumon Y and Terada Y: High glucose induces transactivation of the alpha2-HS glycoprotein gene through the ERK1/2 signaling pathway. J Atheroscler Thromb 16: 448-456, 2009.

37. Ku PM, Chen LJ, Liang JR, Cheng KC, Li YX and Cheng JT: Molecular role of GATA binding protein 4 (GATA-4) in hyperglycemia-induced reduction of cardiac contractility. Cardiovase Diabetol 10: 57, 2011. 